\title{
Comparative Gross and Surface Morphology of the Oropharynx of the Hooded Crow (Corvus cornix) and the Cattle Egret (Bubulcus ibis)
}

\section{Eid A. Moussa and Said A. Hassan}

Department of Anatomy and Embryology, Faculty of Veterinary Medicine, Suez Canal University, Ismailia, Egypt

\section{Abstract}

Ten adult hooded crow and another ten adult cattle egret were used to study the oropharyngeal cavity macro and microscopically. The oropharynx in both birds was a dorsoventrally flattened tube, presented four openings, choanal and infundibular slits in the roof and glottis and oesophageal opening in the floor. The choanal slit divided into rostral and caudal part in hooded crow while in cattle egret it was undivided. The roof of oropharynx presents infundibular slit in midline. The horny conical papillae were widely distributed in the roof and floor of the oropharynx of hooded crow while in cattle egret it was absent except two rows in the roof of oropharynx. The opening of salivary glands ducts were widely distributed in the roof and floor of the oropharynx of the hooded crow while in cattle egret they were few in number only in the caudal part of the roof of the oropharynx. The microfolds in both birds are present in the roof of the oropharynx but absent in the floor. The cattle egret is characterized by the presence of hills and deep microgrooves in addition to micropits.

Keywords: Oropharynx, Hooded crow, Cattle egret

\section{Introduction}

The Hooded Crow (Corvuscornix) is an opportunistic generalist predator and scavenger using mostly visual cues to find a widerange of food including grain, small mammals, carrion and rubbish (Coombs, 1978; Yom-Tov 1974; and Cocker et al., 2005). It is a major predator of bird's eggs and young (Mehlum 1991, Luginbuhl et al. 2001, Sullivan and Dinsmore 1990) and as such is targeted as a pest species especially in bird game industries wishing to 
maximize fledging success (Coombs, 1978).

The Cattle Egret (Bubulcus ibis)feeds on a wide range of prey, particularly insects, especially grasshoppers, crickets, flies (adults and maggots) (Seedikkoya et al., 2007), and moths, aswell as spiders, frogs, and earthworms (Siegfried,1971; Fogarty et al., 1973). In a rare instance they have been observed foraging along the branches of a Banyan tree (Chaturvedi, 1993). The role of this bird in management of insect pests in different agro-ecosystems is also reported (Yadav, 2000 and Middlemiss, 1955). In South Africa they give much importance as controller of dipterous pests of cattle (Blaker, 1969). Ali (2002) and Siegfred (1972) have recorded presence of pray items as green blowfly of the family califorida in the food of this bird.

We carried out this study to obtain some information about the gross anatomical features of the oropharyngeal cavity in hooded crow as omnivourus bird and cattle egret as carnivourous bird. Such information serves a good knowledge in understanding the different mechanisms of feeding and drinking habits.

As birds were devoid of soft palate, glossopalatine arch and epiglottis; the anatomical features of the avian oropharyngeal cavity was completely different from that of mammals. McLeod (1939) and Hamilton(1952) in fowl; Nickel et al. (1977) in domestic birds; Dyce et al. (2002) in chicken considered that the oropharynx was a combined cavity extending from the beak to the oesophageal opening and they described the oropharynx as a part of this cavity. Moreover, information on the morphology of the oropharynx of bird species was very little. Therefore the present study was carried out on the oropharyngeal cavity of hooded crow and cattle egret as examples of omnivorous and carnivorous wild birds. We described the morphology of the oropharynx of both birds grossly and by the scanning electron microscope

\section{Material and Methods}

The current work was performed on ten adult apparently healthy crows and another ten of cattle egrets of both sexes. The birds were divided into two groups five of each species for gross description and the other five for scanning electron microscopy.

The first group was examined by the naked eye and photographed by a digital camera (canon $100 \mathrm{X}$ ). 
For scanning electron microscopy; birds were slaughtered then parts from the mucosa of the roof and floor of the oropharynx were taken and put it in fixative (glutraldehydeparaformaldehyde buffer $(1 \%$ paraformaldehyde and $1.5 \%$ glutralde-hyde in $0.1 \mathrm{M}$ phosphate buffer, $\mathrm{PH} 7.2)$ ) for $2 \mathrm{~h}$ at $4 \mathrm{c}^{\circ}$. These parts were cut into small pieces. The pieces were washed with the same buffer then put in $0.1 \%$ osmium tetraoxide in the same buffer for $2 \mathrm{~h}$. the specimens were then dehydrated in graded series of ethanol followed by critical-point drying carbon dioxide. The specimens then sputter-coated with gold before being examined by a JEOL-5400 LV scanning electron microscope.The anatomical nomenclature used was based on NominaAnatomicaAvium (Baumel et al., 1993) whenever possible.

\section{Results}

\section{Gross morphology}

The oropharynx in both hooded crow and cattle egret has four openings; the choanal slit, infundibular cleft on the roof (figs 1a, 2a, 1b\& $2 b)$, laryngeal cleft and oesophageal opening on the floor (figs 1a, 1b, $3 a \& 3 b)$. The wide caudal part of the choanal slit is located at the same level of the laryngeal cleft (figs $1 \mathrm{a}$, $2 a, 1 b \& 2 b)$. The total length of the oropharyngeal cavity was about 3.5 $\mathrm{cm}$ in the hooded crow and $3 \mathrm{~cm}$ in the cattle egret. The choanal slit constituted about $51 \%$ in hooded crow and $50 \%$ in cattle egret of the total oropharyngeal length. In hooded crow the rostral part of the choanal slit was narrow long formed about $60 \%$ of the total length of the choanal slit while the caudal part was wider and shorter formed about $40 \%$ as compared with that of the narrow part. Unlike hooded crow, the choanal slit in cattle egret was elliptical and undivided into wide and narrow parts. The laryngeal cleft measured about $1.2 \mathrm{~cm}$ in hooded crow and $0.7 \mathrm{~cm}$ in cattle egret and formed about $34 \%$ in hooded crow and $20 \%$ in cattle egret of the total oropharyngeallengh.

\section{Roof of the oropharynx (figs 1, 2,}

\section{4, 5)}

On both edges of the choanal cleft in hooded crow there is row of caudally directed pointed papilla which increased in length gradually toward the caudal end (fig 2a) but in cattle egret, these papillae are found on longitudinal mucosal fold which located about $5 \mathrm{~mm}$ lateral to the lateral border of the choanal slit (fig $2 b)$. In both birds the two ends of the infundibular cleft are free from papillae (figs 1a, 2a, 1b\& 2b). In hooded crow there are about four 
longitudinal rows of short papillae found on the wall of the roof of the oropharyngeal cavity (fig. 3a) while the cattle egret did not have these papillae (figs $1 b \& 2 b$ ).

\section{Floor of the oropharynx}

The U-shaped arrangement of the caudally directed conical papillae in hooded crow were observed at the base of the tongue (fig $3 a$ ) while in cattle egret these papillae were absent (fig 3b). At both ends of this row there are 2-3 long pointed papillae (fig 3a) while in cattle egret there is only one long pointed papillae on each side (fig3b). The edges of the root of the tongue in hooded crow carry irregularly arranged thread-like caudally directed papillae (fig 3a) but cattle egret lack these papillae (fig 3b). In hooded crow the laryngeal mound carries one longitudinal row of long papillae along the border of glottis (fig $3 a$ ) but the cattle egret misses this row of papillae(fig $3 b)$. The caudal border of laryngeal mound carry a transverse row of papillae in cattle egret (fig $3 b$ ) while the crow lacks this row of papillae (fig 3b). In hooded crow there are two oblique transverse rows of medium sized caudally directed laryngeal papillae lie parallel to the midline at the caudal part of the laryngeal mound (fig. $3 b$ ) but the cattle egret lakes this row of papillae(fig $3 b)$.

\section{Scanning electron microscopy}

The prechoana region in the hooded crow showed moderate desquamation of the superficial cells of the epithelium (figs 4/1,4/2), conical horny papillae(fig 4/1), and oval to circular openings of the excretory ducts of the palatine salivary glands (figs $4 / 1,4 / 2$ ). The opening surrounded by concentric arrangement of the surface cells, many of which were in a process of desquamation (fig 4/2). There is a release of desquamated cells and glandular secretion from the glands openings (fig4/2). The surface epithelium showed microfolds (fig 4/2). In the cattle egret this region showed moderate desquamation of the superficial cells of the epithelium (figs $6 / 1,6 / 2$ ), conical horny papillae (fig $6 / 1$ ), the surface of mucous membrane was folded forming numerous microridges (figs 6/1,6/2)and no openings of the excretory ducts of the salivary glands were seen in the examined speciemens (figs $8 / 1,8 / 2$ ).

The choanal region showed higher number of openings of excretory ducts of the palatine salivary glands than the prechoanal region (fig 4/4). The desquamation of the superficial cells of the epithelium was less than the prechoanal region (fig 4/4). The conical horny papillae were present here also(figs $4 / 3,4 / 4$ ). The surface epithelium showed microfolds(fig 
4/4). This region in cattle egret showed no openings of excretory ducts of the salivary glands (figs $6 / 3,4)$. The desquamation of the superficial cells of the epithelium was less than the prechoanal region (figs $6 / 3 \& 6 / 4)$. No conical horny papillae were seen here (figs 6/3,6/4). This region presented numerous grooves in the surface dividing the surface into alternating hills (figs6/3). These grooves were shallow in some areas and deep in others (figs6/3)

The postchonal region of the palate in hooded crow contained rows of large stout short conical horny papillae (fig 4/5). The desquamation of the superficial cells of the epithelium was indistinct (figs $4 / 5 /, 6$ ). The openings of the excretory ducts of the palatine salivary glands were smaller in number than the previous region (fig 4/6). This region in cattle egret contained no conical horny papillae (figs 6/5)The desquamation of the superficial cells of the epithelium was moderate. The openings of excretory ducts of the palatine salivary glands were found in this region. There is a release of desquamated cells and glandular secretion from these openings. The surface of the mucous membrane showed numerous depressions (fig 6/6).

The dorsal surface of the tongue was smooth as the desquamation of the superficial cells of the epithelium was indistinct (fig 5/1). The surface had oval to circular openings of excretory ducts of the lingual salivary glands that surrounded by concentric arrangement of the surface cells (fig 5/1). The dorsal surface of the tongue in cattle egret was smooth as the desquamation of the superficial cells of the epithelium was indistinct (fig $7 / 1,7 / 2$ ). The surface had numerous oval to circular openings of excretory ducts of the lingual salivary glands that surrounded by concentric arrangement of the surface cells (figs $7 / 2,7 / 3$ ). The surface of the mucous membrane showed numerous depressions (figs $7 / 1,7 / 2)$.

The dorsal surface of the laryngeal mound had a large number of the conical long horny pointed papillae (figs $5 / 2,5 / 3,5 / 4$ ). The length of these papillae was greatly increased at the margin of glottis (fig 5/2). some of these papillae had desquamated epithelial cells (fig 5/4). The dorsal surface of the laryngeal mound in cattle egret had no conical horny (fig 7/4). The dorsal surface of the tongue was smooth as the desquamation of the superficial cells of the epithelium was indistinct (fig $7 / 4$ ). The surface of the mucous membrane showed numerous depressions (pits) (fig 7/4). 


\section{Discussion}

The line of demarcation between the oral and pharyngeal cavities in both hooded crow and cattle egret is indefinite. These findings are in accordance with that reported by McLelland(1975) in domestic birds. The pharyngeal cavity extended from the caudal lingual papillae and rostral end of choanal slit to the pharyngeo-oesophageal opening. These results are on line with that recorded by Mcleod (1939) and Hamilton (1952) in fowl and Dyce et al. (2002) in chicken while Hodges (1974) mentioned that the oropharyngealcavity in fowl extend caudally until the glottis. Moreover, King and McClelland (1984) stated that the rostral limit of the oropharyngeal cavity in avian is between the choanal and infundibular clefts while, Nickel et al.(1977) mentioned that it is at the rostral end of infundibular cleft. Functionally, the rostral limit of the oropharyngeal cavity in birds is between the rostral narorrow and caudal wide parts of the choanal slits (Nickel et al., 1977). The current study was in consistence with that stated by the previously mentioned authors that he choanal slit formed only one half of the total length of the oropharyngeal cavity. On the other hand, McClelland (1975\&1979) in ducks, herons and ratites stated that the choanal slit was usually short restricted to the caudal part of the palate with the wide caudal part was longer than the rostral narrow part. Nickel et al. (1977) concluded that the size of the choanal slit in domestic birds depends on the size and shape of the beak. Hodges (1974), McClelland (1975), Nickel et al. (1977), King and McLelland (1984) and Dyce et al. (2002) added that this area is lined by keratinized epithelium because it was usually subjected to wear and tear. Hodges (1974), McLelland (1975), Nickel at al. (1977), King and McClelland (1984) and Dyce et al. (2002) stated that the lamina propria sends projections leads to elevation of the mucosal surface forming the mucosal horny papillae. These results were in accordance with the findings of the current study. The present study found also a clear difference in the distribution and number of the horny papillae between cattle egret and hooded crow. In accordance with Gardner(1926\&1927).

The present study stated that the transverse row of horny papillae at the base of the tongue in hooded crow were long, pointed, strong and caudally directed suggesting that this adaptive feature may help in directing of the food caudally to the esophagus and prevent regurgitation. This row of papillae was absent 
in cattle egret except one lateral long papilla on each side of the base of the tongue, we suggest that the absence of this row also may be due to the difference in the food nature of eating worms (soft pliable food not bulk).

The current study suggested that the papillae around the glottis to prevent any foreign body from entering the respiratory passage. On other hand the cattle egret had no papillae around the glottis but hooded crow had more than one row of papillae and we suggested that is due to the difference in feeding habit the crow eat bulk rough food while cattle egret is carnivorous eating soft food.

Regarding the salivary glands there is a clear difference between the hooded crow and cattle egret that in hooded crow the salivary glands distributed all over the wall of the oropharynx except on the laryngeal mound while in cattle egret the it was absent except on the root of the tongue and the postchoanal region of the palate. This difference suggested due to the different feeding habit that the hooded crow eat rough dry food while cattle egret eats soft pliable slippery food. Our suggestion was in accordance with that reported by Strukie (1976) that the avian species that ingest slippery aquatic food have poorly de- veloped salivary glands while those eat dry food have well-developed ones. On other hand King and McClelland (1984) mentioned that the salivary glands were absent totally in some birds as Great cormorants.

Most of the salivary glands in hooded crow showed mucous secretion while in cattle egret no mucous were seen in the duct openings. On other hand King and McClelland (1984) and Hodges (1974) stated that the mucous secreting gland in the oropharynx in bird were the caudal palatine and sphenoptrygoid salivary glands only but McLelland (1975) described only the sphenoptrygoid glands while Samar et al. (1999) mentioned only the palatine salivary glands.

The salivary glands in the floor of the oropharynx in both birds in the current study represented by the caudal lingual salivary glands. On the other hand Hassona (2002) in duck, King and McLelland (1984) and Hodges (1974) in domestic birds stated that in represented by caudal lingual and cricoarytenoid glands. Moreover, McLelland (1975) and Nickel et al. (1977) mentioned only the cricoarytenoid salivary gland but the first author termed them lateral and medial laryngeal while the second author termed them laryngeal salivary gland. 


\section{References}

Ali(2002): The book of Indian birds. $13^{\text {th }}$ ed. Bombay Natural History Society \&Oxford University Press, $326 \mathrm{pp}$.

Baumel, J.J.(1993): In NominaAnatomicaAvium. ed. by Baumel, J.J.; King, A.S.; Lucas, A.M.; Breazile, J.E. and Evans, H.E., London, New York, Academic Press.

Blakar B. R.(1969):Behaviour of the cattle egret. Ostrich 40 (3): 75-129

Chaturvedi, N.(1993): Dietary of the cattle egret Bubulcus ibis coromandus (Boddaert), Journal of the Bombay Natural History Society 90 (1): 90.

Cocker, Mark; Mabey, Richard(2005): Birds Britannica. London: Chatto\&Windus. pp. 418-425. ISBN 0-7011-6907-9.

Coombs, F.(1978): The crows: a study of the corvids of Europe, Batsford.

Dyce, K.M.; Sack, W.O. and Wensing, C.J.G.(2002): Textbook of Veterinary Anatomy, 3rd ed., Pp. 823,824. Saunders, Philadelphia, London, New York, St. Louis, Sydney, Toronto.
Fogarty, Michael J.; Hetrick, Willa Mae(1973): Summer Foods of Cattle Egrets in North Central Florida, The Auk 90 (2): 268-280.

Gardner, L.L.(1926): The adaptive modification and taxonomic value of the tongue in birds. Proc. US.Natn, Mus. 27 Art. 19.

Gardner, L.L.(1927): On the tongue in birds, Ibis, 3, 185-196

\section{Hofer,}

H.(1945):Untersuchengenüber denbau des vogelschadels, basondersüber den derSpechte und steisshuhner, Zool. Jb. (Abt Anat. V. Ontogenie d. tiere): 69. Pp. 1-158.

Hamilton, H.L.(1952): In Lillie, s "development of the chick" $3^{\text {rd }}$ Ed. New York, Henery Holt and Comp. INC.

Hassouna E.M.(2002): Morphological studies on theoropharyngeal cavity of duck (Anasboushiusdomesticus), Assiut Vet. Med. J. 47(94) pp.:21-41

Hodges, R.D.(1974): The digestive system in "The histology of the fowl". Academic press INC. London, LTD. 
King, A.S. and McLelland, J.(1984): Birds, their structure and function, 2nd ed., Pp. 43-51, Bailliere, Tindall, London, Philadelphia, Toronto, Mexico, Rio de Janeiro, Sydney, Tokyo, Hong Kong.

Luginbuhl, J. M., Marzluff, J. M., Bradley, J. E., Rabhael, M. G. and Varland, D. E.(2001):Corvid survey techniques and the relationship between corvid relative abundance and nest predation. -Journal of Field Ornithology, 72: 556- 572.

Mehlum, F.(1991): Egg predation in a breeding colony of the Common Eider Somateriamollissima in Kongsfjorden, Svalbard. -SkrifterNorskPolarinstitutt: 37-45.

McLelland,J.(1975): Avis digestive system in king and McLelland, Vol. I. $5^{\text {th }}$ ED. London, New York, Toronto, Sydney, San Francisco.

McLelland,J.(1979): Avis digestive system in Sisson and Grossman's "the anatomy of the domesticanimals" Getty, R. Vol. II. $5^{\text {th }}$. Philadelphia, Saunders, London, Toronto.

Mcleod, W.M.(1939): Anatomy of the digestive system of the domestic fowl. Vet. Med., 34, 722-727

Middlemiss E H J(1955): Food of egrets. Ostrich 26: 159.
Nickel,R. ;Schummer,A. and Seiferle, E.(1977):Anatomy oftheDomestic Birds, chapter (blood and vascular system),Verlagpaulparey,Berlin and Hamburg. pp. (96-99).

Samar, Avila, De Fabro, Porfrio, Esteba, Pedrosa and Peinado(1999):Histochemical studies of magellanic penguin minor salivary glands during postnatal growth Ana., Rec. 1, 254(22):298-306.

Seedikkoya K, PA Azeez, EA Abdul Shukkur.(2007):Cattle egret as a biocontrol agent. Zoos' Print Journal 22 (10): 2864-2866.

Siegfried, W. R.(1971): The Food of the Cattle Egret. Journal of Applied Ecology (British Ecological Society) 8 (2): 447-468. doi:10.2307/2402882.JSTOR 24028 82.

Siegfried W. R.(1972): Aspects of feeding ecology of cattle egret in south Africa. Journal animal ecology 41 (71-78).

Strukie, P. D.(1976):Alimintary tract, anatomy, prehension, deglutition, feeding, drinking, passage of ingesta and motility. In "Avian physiology" Strukie. P.D. New York Springer Verlag. 
Sullivan, B. D. and Dinsmore, J. J.(1990): Factors affecting egg predation by American crows. Journal of Wildlife Management, 54: 433437.

Yom-tov, Y.(1974): Effect of food and predation on breeding density and success, clutch size and laying date of crow (Corvuscorone). Journal of Animal Ecology, 43: 479497.

Yadav D. N.(2000): All India network project on agricultural ornithology: annual report. Gujarat agriculture university, Anand, 1-14
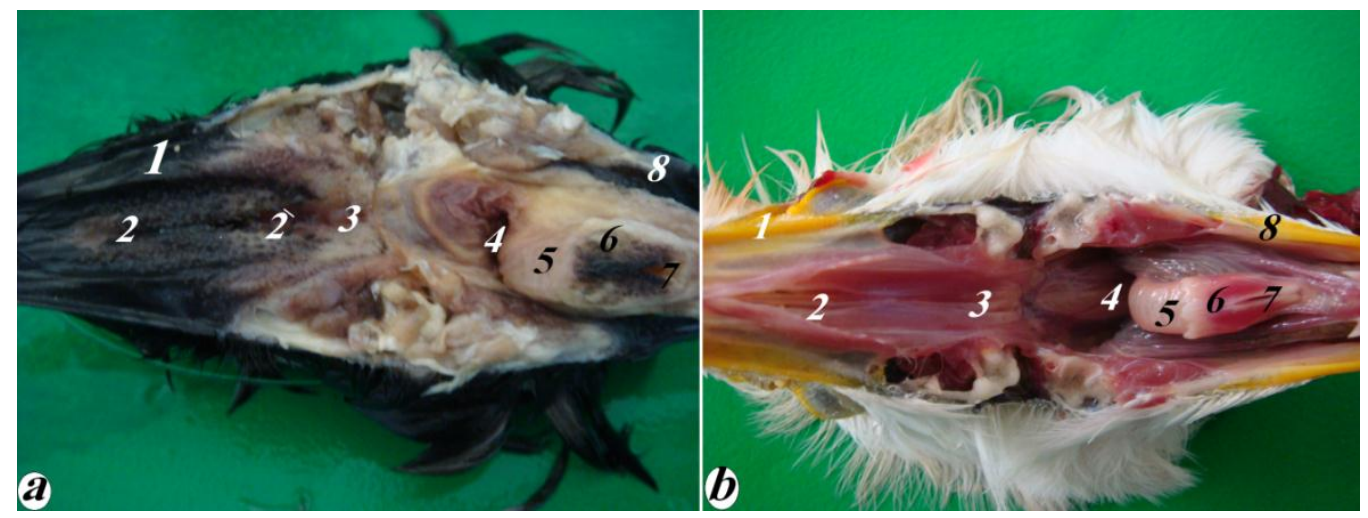

Fig (1): a photograph of the roof of the oropharyngeal cavity of the hooded crow (a) and cattle egret (b) showing:1- Rostrum maxillare, 2- Choana, Pars rostralis , 2'-Choana, Pars caudalis , 3- Rima infundibuli 4- Oesophageal opening, 5-Trachia, 6-Mons laryngealis, 7-Glottis, 8- Rostrum mandibulare, 

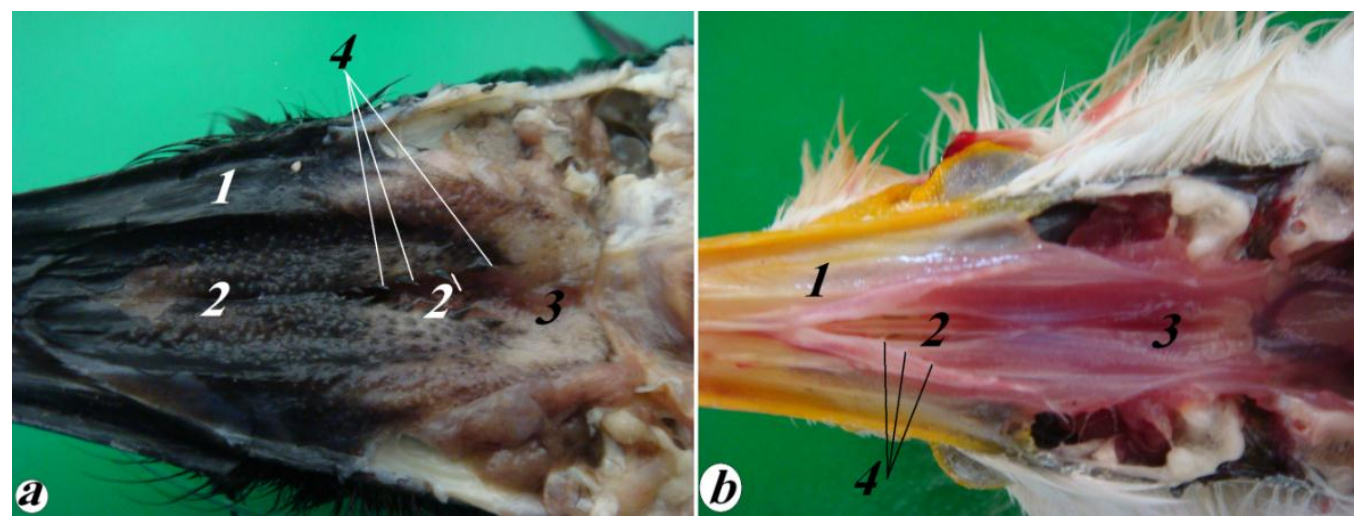

Fig (2): a photograph of the roof of the oropharyngeal cavity of the hooded crow (a) and cattle egret (b) showing:1- Rostrum maxillare, 2- Choana, Pars rostralis , 2'-Choana, Pars caudalis , 3- Rima infundibuli, 4- Horny papillae

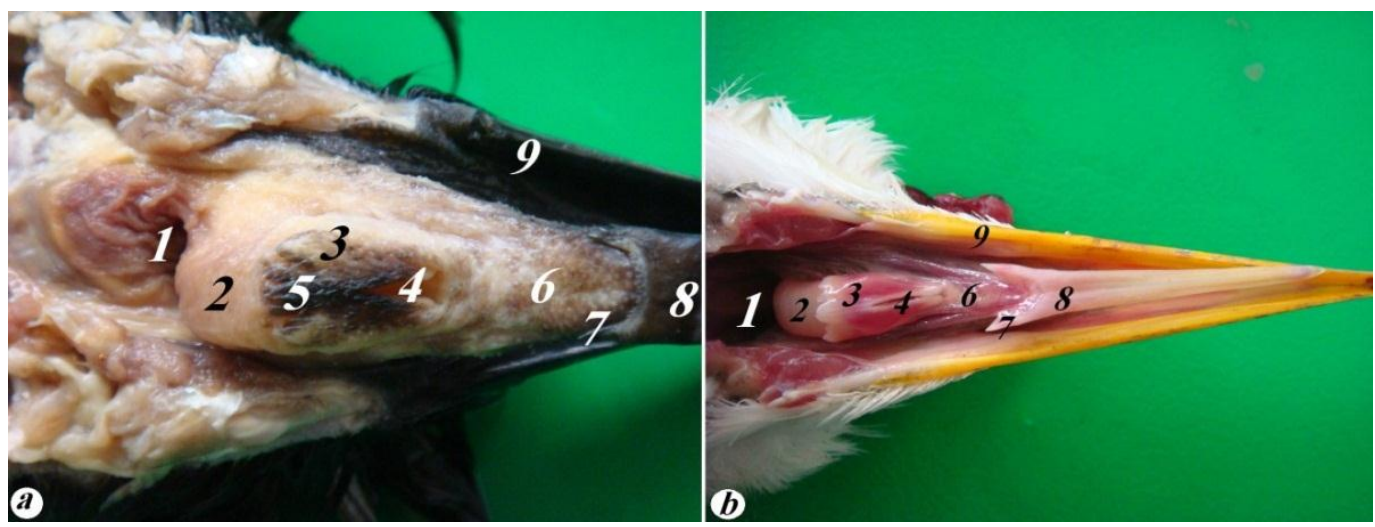

Fig (3): a photograph of the floor of the oropharyngeal cavity of the hooded crow(a) and cattle egret (b) showing: 1- Oesophageal opening, 2-Trachia, 3- Mons laryngealis, 4Glottis, 5- Horny papillae, 6- Radix linguae, 7- U-shaped arrangement of the conical papillae, 8- Corpus linguae, 9- Rostrum mandibulare. 

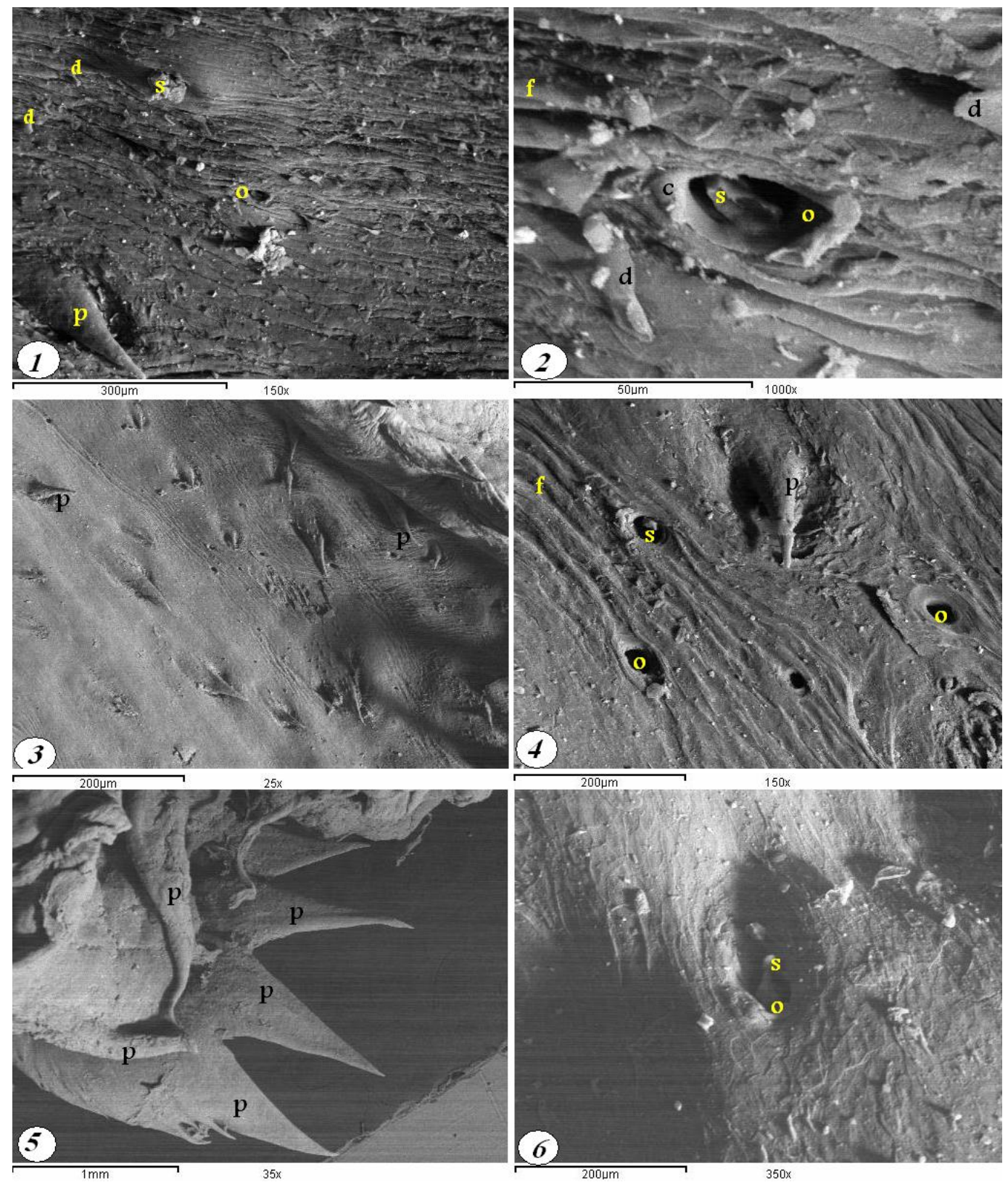

Fig (4): Micrograph of the roof of the oropharynx of hooded crow: the prechoanal region (1\&2), choanal region (3\&4), postchoanal region (5\&6), Conical horny papilla (p), Opening of the excretory ducts of salivary glands(o), Desquamated squamous epithelial cells(d), Mucous secretion of the salivary glands(s), Concentric arranged keratinized cells around the opening of the excretory ducts of salivary glands(c). 

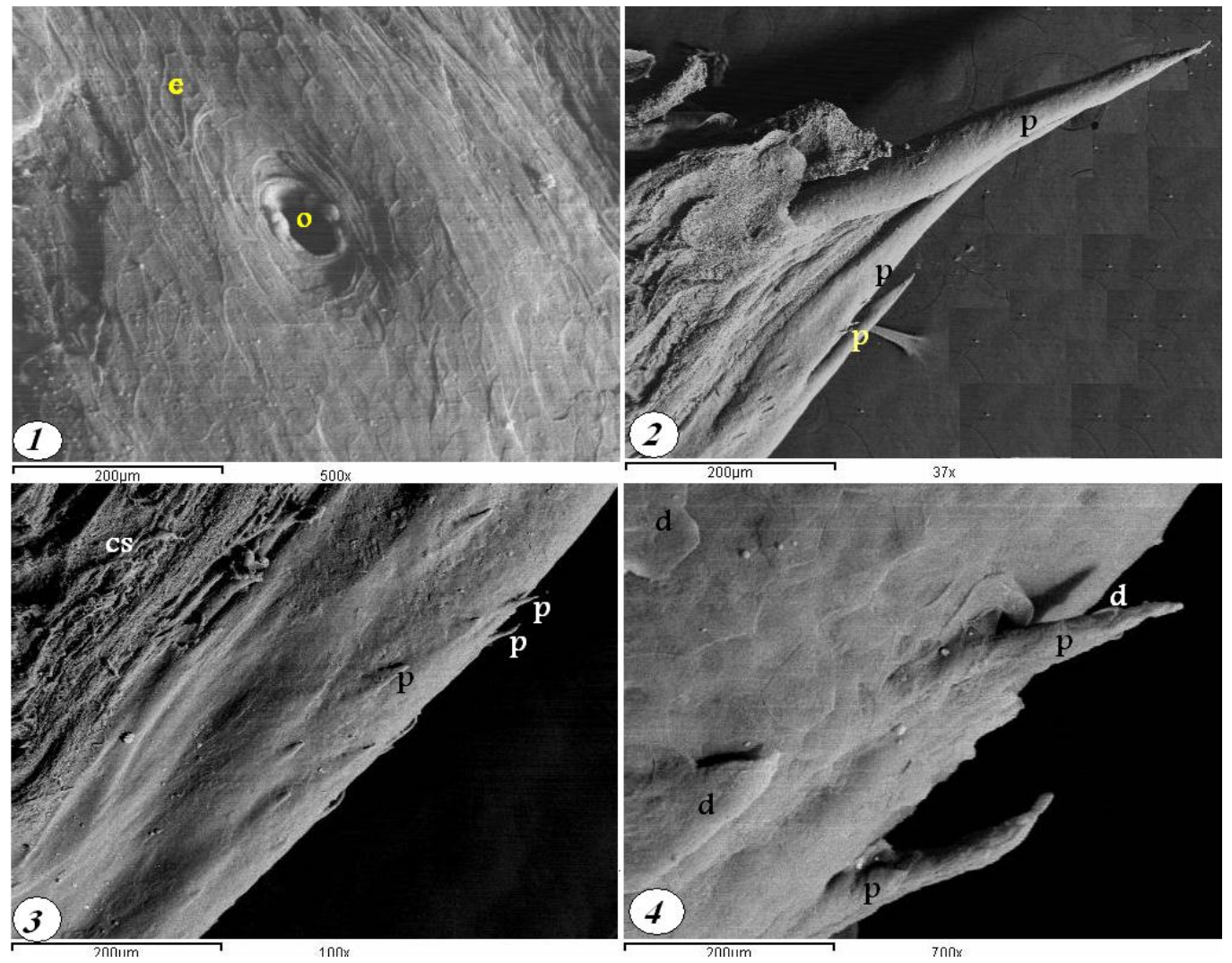

Fig (5): Micrograph of the floor of the oropharynx of hooded crow: root of tongue (1), laryngeal mound $(2,3 \& 4)$, Conical horny papilla(p), Opening of the excretory ducts of salivary glands(o), Desquamated squamous epithelial cells(d), Cut surface(Cs), Epithe$\operatorname{lium}(e)$. 

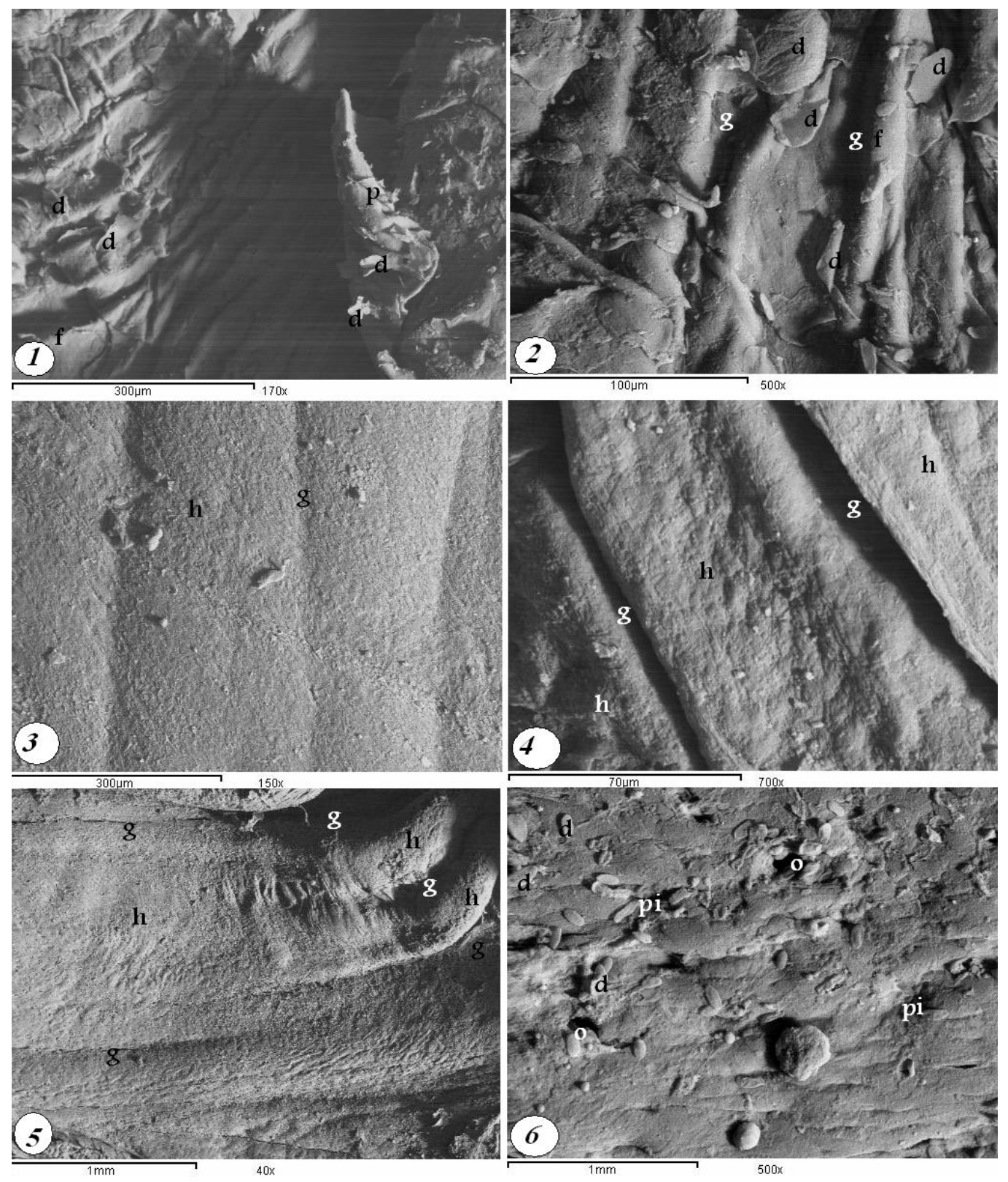

Fig (6): micrograph of the roof of the oropharynx of cattle egret: prechoanal region (1\&2), choanal region (3\&4), postchoanal region (5\&6), Conical horny papilla(p), Opening of the excretory ducts of salivary glands(o), Desquamated squamous epithelial cells(d), Microgroove(g), Hill(h), Micropit(Pi) 

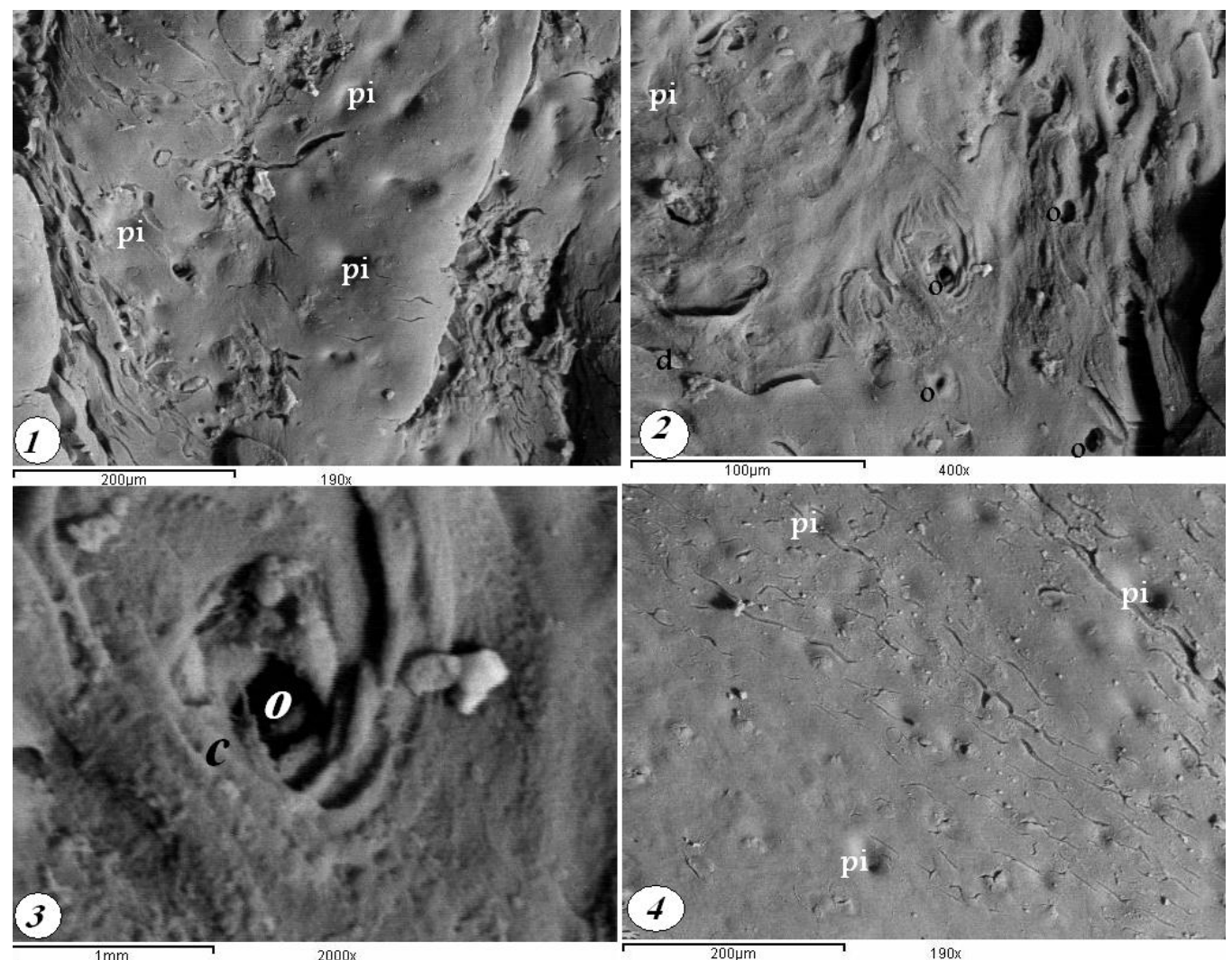

Fig (7): micrograph of the floor of the oropharynx of cattle egret: root of tongue $(1,2 \& 3)$, laryngeal mound (4), Opening of the excretory ducts of salivary glands(o), Micropit (Pi), Concentric arranged keratinized cells around the opening of the excretory ducts of salivary glands(c). 